\title{
Value chains for carbon storage and enhanced oil recovery: optimal investment under uncertainty
}

\author{
Stein-Erik Fleten • Kristin Lien • Kristin Ljønes • \\ Adela Pagès-Bernaus • Marte Aaberg
}

Received: 6 September 2010 / Accepted: 7 October 2010 / Published online: 28 October 2010

(C) The Author(s) 2010. This article is published with open access at Springerlink.com

\begin{abstract}
Carbon capture and sequestration is a possible technology for abating carbon dioxide emissions. This is costly and requires investment in capture, transportation and storage facilities, and compensation for possibly substantial operational cost at these facilities. On the other hand, this option avoids buying carbon offsets, and the $\mathrm{CO}_{2}$ may in some cases be used for enhanced oil recovery. Stochastic dynamic programming is applied to perform the underlying investment analysis, that is, to decide whether investment on a $\mathrm{CO}_{2}$ value chain is profitable, and if so, then when the decisions should be taken. The oil and $\mathrm{CO}_{2}$ prices are modelled as stochastic processes. As a case study we consider possible $\mathrm{CO}_{2}$ value chain investments on the Norwegian Continental Shelf.
\end{abstract}

Keywords $\mathrm{CO}_{2}$ value chain - Carbon capture and storage - Enhanced oil recovery Dynamic programming · Greenhouse gas abatement · Energy price uncertainty

\section{Introduction}

The abatement of carbon dioxide emissions is high on the agenda of politicians, researchers and main $\mathrm{CO}_{2}$ emitters. In 2007, the European Union leaders committed Europe to transforming itself into a highly energy-efficient, low-carbon economy. The main goals are known as the 20-20-20 targets, that is in 2020, a reduction in greenhouse gas emissions of at least $20 \%$ compared to 1990 levels, to produce $20 \%$ of the energy consumed from renewable sources and a $20 \%$ reduction in primary

S.-E. Fleten · K. Lien · K. Ljønes · A. Pagès-Bernaus $(\varangle) \cdot$ M. Aaberg Department of Industrial Economics and Technology Management, Norwegian University of Science and Technology, Trondheim, Norway

e-mail: Adela.Pages@iot.ntnu.no

S.-E. Fleten

e-mail: Stein-Erik.Fleten@iot.ntnu.no 
energy use, to be achieved by improving energy efficiency. This climate and energy package became law in June 2009. The core of the package is composed of four main points: an improvement of the Emissions Trading System (EU ETS) so it becomes the driver for cutting emissions cost-effectively, an "Effort Sharing Decision" that covers other sectors not included in the EU-ETS, targets for renewable energy, and a legal framework to promote the development and safe use of carbon capture and storage (CCS).

The promotion of CCS is based on the observation that fossil fuels will remain the primary source of energy worldwide for the decades to come. The carbon emissions reduction target will never be met unless the energy production coming from fossil fuels can be exploited without ballooning emissions. Clearly CCS has the potential to contribute to the EU's climate goals [12].

Carbon capture and geological storage is a technique for trapping carbon dioxide from large emitters by separating the $\mathrm{CO}_{2}$ from the flue gas, conditioning it, compressing it, and transporting it to a suitable storage site (such as aquifers) where it is injected for a safe and long-term storage. Although the components of CCS are all known, the integration into one system is new. One of the main challenges for CCS is the economic burden. Significant up-front investments are required, and the energy penalty during capture is high (in the order of 10-40\% [11]). If the geographical situation is favourable or infrastructure is in place, then $\mathrm{CO}_{2}$ can be used for improving the recovery of oil. When oil production with conventional methods declines, enhanced oil recovery (EOR) methods allow additional oil to be extracted economically from the reservoir and increase the producer's revenues. In some oil fields, $\mathrm{CO}_{2}$ can be used to displace additional oil that otherwise would remain in the reservoir. ${ }^{1}$

Within Europe large $\mathrm{CO}_{2}$ emitters need to hold emission rights for each tonne of $\mathrm{CO}_{2}$ emitted. When a company emits more $\mathrm{CO}_{2}$ than the amount of allowances owned, the company has to offset the exceeded carbon emissions by for example buying emission rights in the Emissions Trading Scheme (EU-ETS) [1], a market where companies can trade $\mathrm{CO}_{2}$ allowances.

$\mathrm{CO}_{2}$ producers within the EU have the choice between buying carbon allowances and investing in carbon capture and storage (CCS) facilities. In this paper, we examine an investment opportunity for CCS with EOR. We focus on upstream investment decisions regarding $\mathrm{CO}_{2}$ storage and use for EOR. We assume that a gas power plant has recently been installed, and we consider three possibilities regarding the treatment of the $\mathrm{CO}_{2}$. One is to vent the $\mathrm{CO}_{2}$ and, therefore, $\mathrm{CO}_{2}$ allowances are required. The second possibility is to invest in a CCS value chain, where the $\mathrm{CO}_{2}$ is stored in a nearby aquifer. The third option is to invest in CCS and also in EOR. This latter option is the one that requires more investment, but there are additional revenues from the extra oil recovered. The analysis can be viewed as an application of real options theory; however, we apply a traditional dynamic programming approach instead of state-contingent (risk neutral) pricing.

Several authors have studied the profitability of investments in CCS. Abadie et al. [2] analyse a coal-fired power plant that has the option to invest in a CCS

\footnotetext{
${ }^{1}$ The emissions due to the extra oil recovered are not considered in this study.
} 
unit. A real options analysis is used to determine the price of $\mathrm{CO}_{2}$ that triggers investment in CCS. Their conclusion is that, with current carbon prices and projected variability, the best practice is to wait for higher $\mathrm{CO}_{2}$ prices. Fuss et al. [5] illustrate how uncertainty around the carbon price due to market and policy fluctuations delays the decision to invest in CCS. Both papers model the $\mathrm{CO}_{2}$ allowance price and the electricity price as two correlated stochastic processes, and the main conclusion is that current $\mathrm{CO}_{2}$ prices do not promote investment in CCS. Heydari et al. [6] study the option to retrofit a coal power plant with full or partial CCS. The coal and the allowances prices evolve as correlated geometric Brownian motion processes. A real option analysis is performed to conclude that, with current market data, the best option in the near term is to wait. In order to increase the chances of having a profitable investment, we extend the value chain with the possibility of EOR.

Gaspar et al. [13] develops a techno-economical model to assess the feasibility of $\mathrm{CO}_{2}$ sequestration in EOR operations. Their conclusion is that EOR with $\mathrm{CO}_{2}$ is economically sound, and that, at the same time, large amounts of $\mathrm{CO}_{2}$ can be stored. While their study focuses on the profitability of $\mathrm{CO}_{2}$-EOR, we look into a complete value chain, with decisions on whether and when to capture and how to store the $\mathrm{CO}_{2}$. Timing of investment is an important property of our analysis. Klokk et al. [9] present a deterministic multiperiod investment model for designing an optimal deployment of a large CCS infrastructure (including EOR). Their model assumes that a fixed set of $\mathrm{CO}_{2}$ producers will install the capture facilities at the beginning of the planning period, and the model chooses the best candidates (either aquifers or oil fields for EOR) for storing the $\mathrm{CO}_{2}$ and the pipelines used. In our model, investing in carbon capture is a possibility that happens only if it is more profitable than venting. In addition to the flexibility on the investment in capture, we treat the future oil and $\mathrm{CO}_{2}$ allowance price as stochastic processes. Our contribution is a stochastic dynamic analysis for $\mathrm{CO}_{2}$ value chains where the use of $\mathrm{CO}_{2}$ for EOR is a possibility in addition to the storage in an aquifer.

A base case is used in order to illustrate how uncertainty in future prices and the flexibility in postponing an investment affects its overall profitability. We consider a natural gas-fired power plant in Norway, which has the possibility of retrofitting the plant with a capture unit and storing the $\mathrm{CO}_{2}$ in a nearby aquifer or using the $\mathrm{CO}_{2}$ for EOR. We assume that the power plant starts its operation in 2012 and has a lifetime of 25 years.

The paper is organised as follows. Section 2 presents the theoretical framework used to perform the investment analysis. Section 3 describes the test case and the parameters used. It concludes with the analysis of the results and main findings.

\section{Dynamic programming framework}

In this paper, we evaluate timing decisions on whether and when a $\mathrm{CO}_{2}$ producer should invest in CCS facilities. We put special emphasis on how the use of $\mathrm{CO}_{2}$ for EOR influences the profitability of CCS and on the timing of investment in the various elements of the $\mathrm{CO}_{2}$ value chain. This section presents the modelling and solution approach. 
Fig. 1 Representation of the binomial lattice used to represent the stochastic processes in discrete time, $\xi_{t}^{k}=\left(P_{t}^{\mathrm{oilk}}, P_{t}^{\mathrm{CO}_{2} k}\right)$

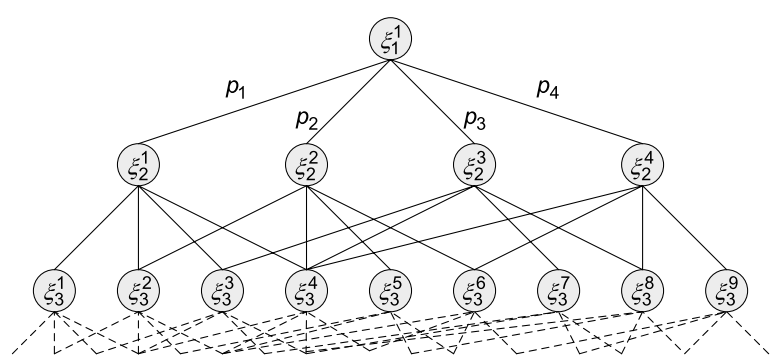

The model considers investment in CCS (with EOR) based on two economic incentives. One is the savings in $\mathrm{CO}_{2}$ allowances, and the other is the extra income due to producing and selling additional oil. In our analysis, $\mathrm{CO}_{2}$ and oil prices are treated as stochastic processes. The price dynamics of commodities may be classified into short-term and long-term factors [14]. The former are transitory and affect current supply and demand, but without a permanent effect on them. Long-term factors, by contrast, are persistent and cause supply and demand changes that last for a long time. The latter phenomenon is usually modelled using a random walk process. Because this analysis deals with strategic investment decisions with a time frame of 25 years, it is assumed that only the long-term uncertainties drive the investment decisions (thus ignoring mean-reverting short-term effects), and the price developments are modelled following a geometric Brownian motion (GBM).

The GBM stochastic process occurs in continuous time and is represented by (1), where $P_{t}$ is the price that changes with the time, $\mu$ is the expected percentage drift, $\sigma$ is the percentage volatility and $Z_{t}$ is a standard Brownian motion process. Given the current price $P_{0}, P_{t}$ follows a log-normal distribution [3]. Both the oil price, $P_{t}^{\text {oil }}$, and the $\mathrm{CO}_{2}$ price, $P_{t}^{\mathrm{CO}_{2}}$, are modelled as correlated GBMs, i.e., $d Z_{t}^{\text {oil }} d Z_{t}^{\mathrm{CO}_{2}}=\rho d t$.

$$
\frac{d P_{t}^{i}}{P_{t}^{i}}=\mu^{i} d t+\sigma^{i} d Z_{t}^{i}, \quad i=\text { oil }, \mathrm{CO}_{2}
$$

An approximation to the GBM process in discrete time is through a binomial lattice (see Fig. 1). Let $\xi_{t}$ be the random variable with the oil and $\mathrm{CO}_{2}$ prices pair $\left(P_{t}^{\text {oil }}\right.$, $\left.P_{t}^{\mathrm{CO}_{2}}\right)$. Each node in the lattice is related to one price state in one specific point in time, $\xi_{t}^{k}$, where $t$ represents the time period and $k$ a particular realization of the uncertainty $\left(P_{t}^{\text {oilk }}, P_{t}^{\mathrm{CO}_{2} k}\right.$ ). In this analysis, the time step used is one year. Because the two commodities are correlated, the prices are modelled using a Rubinstein nonrectangular lattice [8], where for a given time period the mean and variance of the lattice are the right values (with respect to the mean and variance implied by (1)) and the prices of the two commodities are related through the parameter $\rho$, where $d Z_{t}^{\text {oil }} d Z_{t}^{\mathrm{CO}_{2}}=\rho d t$.

The owner of the value chain faces the decision of how to treat the $\mathrm{CO}_{2}$ produced and wishes to maximise the sum of discounted expected future profits by taking the best decision at the right moment. Dynamic programming (DP) is well suited to solving optimisation problems that combine time, uncertainty and can be decomposed into subproblems. DP defines two types of variables: state variables and decision 
variables. The state variables at each node $k, s_{t}^{k}$, define the state of the system at time $t$ : oil and $\mathrm{CO}_{2}$ prices, $\xi_{t}^{k}$, and level of investment. Here there are two possible states regarding the treatment of the $\mathrm{CO}_{2}$ : to vent or to capture the $\mathrm{CO}_{2}$; and three possible states regarding the storage of $\mathrm{CO}_{2}$ : no storage, storage in an aquifer, or using the $\mathrm{CO}_{2}$ for EOR. The decision variables, $x_{t}^{k}$, are the set of possible actions that can be taken: to invest in $\mathrm{CO}_{2}$ capture, to invest in storage in the aquifer or to invest in EOR activity.

At each period $t$, some choices are available to the firm, so a transition matrix, $\tau_{t}$, is used to determine how the system can evolve from period $t$ to period $t+1$. Also the state and decision variables at time $t, s_{t}^{k}$ and $x_{t}^{k}$, affect the probability distribution of future states. Let $\phi_{t}^{k}\left(s_{t+1} \mid s_{t}^{k}, x_{t}^{k}\right)$ denote the probability density function of the state next period, conditional upon the current information. This function is built from the transition matrix, $\tau_{t}$, and the representation of the stochastic components, $\xi_{t}^{k}$.

Given a realization of the uncertainty at time $t, \xi_{t}^{k}$, the immediate profit $\pi_{t}\left(s_{t}^{k}, x_{t}^{k}\right)$ can be calculated. The yearly profits of the owner of the value chain with respect to the treatment of the $\mathrm{CO}_{2}$ (2) are composed of the oil revenues minus the cost of buying $\mathrm{CO}_{2}$ allowances minus variable costs for operating the CCS system (with EOR) minus the investment costs faced in this period.

$$
\pi_{t}\left(s_{t}^{k}, x_{t}^{k}\right)=P_{t}^{\mathrm{oil} k} q_{t}^{\mathrm{oil}}\left(s_{t}^{k}\right)-P_{t}^{\mathrm{CO}_{2} k} q_{t}^{\mathrm{CO}_{2}}\left(s_{t}^{k}\right)-c_{t}^{\mathrm{op}}\left(s_{t}^{k}\right)-c_{t}^{\mathrm{inv}}\left(x_{t}^{k}\right)
$$

$P_{t}^{\text {oilk }}$ and $P_{t}^{\mathrm{CO}_{2} k}$ are the prices of $\mathrm{CO}_{2}$ and oil in state $s_{t}^{k}, q_{t}^{\text {oil }}\left(s_{t}^{k}\right)$ is the amount of oil produced, $q_{t}^{\mathrm{CO}_{2}}\left(s_{t}^{k}\right)$ is the amount of $\mathrm{CO}_{2}$ emitted and $c_{t}^{\mathrm{op}}\left(s_{t}^{k}\right)$ are the operational costs. These quantities are different depending on the state of the system. The quantity $c_{t}^{\text {inv }}\left(x_{t}^{k}\right)$ corresponds to the investment costs incurred by making decision $x_{t}^{k}$.

Let $F_{t}\left(s_{t}^{k}\right)$ express the expected net present value (NPV) of all cash flows of being in state $s_{t}^{k}$, when all decisions from time $t$ onwards are made optimally:

$$
F_{t}\left(s_{t}^{k}\right)=\max _{x_{t}^{k}}\left\{\pi_{t}\left(s_{t}^{k}, x_{t}^{k}\right)+\frac{1}{1+r} \mathbb{E}_{t}\left[F_{t+1}\left(s_{t+1}\right)\right]\right\}
$$

where $r=0.055$ is the discount rate. Since we are in a stochastic setting the set of optimal decisions at time $t+1$ will yield $F_{t+1}\left(s_{t+1}\right)$, which is a random quantity from the perspective of period $t$. Therefore the expected value (4) is taken. ${ }^{2}$ This expected value is called continuation value, and it has to be discounted to time $t$. The owner of the value chain will choose the decision $x_{t}$ that maximises (3).

$$
\mathbb{E}_{t}\left(F_{t+1}\left(s_{t+1}\right)\right)=\sum_{l=1}^{4} \phi_{t}^{k}\left(s_{t+1}^{l} \mid s_{t}^{k}, x_{t}^{k}\right) F_{t+1}\left(s_{t+1}^{l}\right)
$$

Equation (3) is applied recursively from the last period, $T$, to the first period. The decision to be made in the last stage, $x_{T}^{k}$, is already known, which is to stay

\footnotetext{
${ }^{2}$ The expression given here for the expected value is adapted for our problem. The general form is: $\mathbb{E}_{t}\left(F_{t+1}\left(s_{t+1}\right)\right)=\int F_{t+1}\left(s_{t+1}\right) d \Phi_{t}\left(s_{t+1} \mid s_{t}^{k}, x_{t}^{k}\right)$ where $\Phi_{t}\left(s_{t+1} \mid s_{t}, x_{t}\right)$ is the cumulative distribution function of $\phi_{t}\left(s_{t+1} \mid s_{t}, x_{t}\right)$ and the range of integration is the support of $\Phi_{t}\left(s_{t+1} \mid s_{t}, x_{t}\right)$.
} 
in the same state as nothing else will occur. Therefore $F_{T}\left(s_{T}^{k}\right)$ is known: $F_{T}\left(s_{T}^{k}\right)=$ $\pi_{T}\left(s_{T}^{k}, x_{T}^{k}\right)$. From there the value $F_{T-1}\left(s_{T-1}\right)$ can be computed with (3). Backward induction is employed until the first period (see [3] for a formal description). The solution procedure in pseudo-code is:

for all nodes of the lattice that belong to period $T$ and state $k$ do

Compute $F_{T}\left(s_{T}^{k}\right):=\pi_{T}\left(s_{T}^{k}, x_{T}^{k}\right)$

\section{end for}

for $t=T-1$ until 1 do

for all nodes that belong to period $t$ do

Compute $\mathbb{E}_{t}\left(F_{t+1}\left(s_{t+1}\right)\right)$ as in (4)

for each possible decision $x_{t}^{k}$ that can be taken from state $s_{t}^{k}$ do

Compute the current profit $\pi_{t}\left(s_{t}^{k}, x_{t}^{k}\right)$ as in (2)

\section{end for}

Compute $F_{t}\left(s_{t}^{k}\right)$ as in (3)

end for

end for

The information obtained from the DP solution is a matrix containing the optimal decision, $x_{t}^{k}$, for every time period $t$, state $s_{t}^{k}$, and pair of price instances $\left(P_{t}^{\text {oil } k}\right.$, $\left.P_{t}^{\mathrm{CO}_{2} k}\right)$. The solution $F_{1}\left(s_{1}^{1}\right)$ is the expected NPV when the investor will follow the strategy (set of optimal decisions at each node of the lattice and state) found by DP.

\section{Case description}

Suppose that a natural gas power plant of $400 \mathrm{MW}$ without capture will be built by 2012. If the power plant is retrofitted with a capture module then 2 tonnes of $\mathrm{CO}_{2}$ per year will be captured. ${ }^{3}$ The study starts in 2012 and we assume that the remaining lifetime of the plant is of 25 years.

The investment possibilities, which define the investment costs $c_{t}^{\text {inv }}\left(x_{t}^{k}\right)$ and the subsequent operational $\operatorname{costs} c_{t}^{\mathrm{op}}\left(s_{t}^{k}\right)$, are:

- CCS system: to install a capture unit that separates, conditions and pressurizes the $\mathrm{CO}_{2}$. The $\mathrm{CO}_{2}$ is transported in a 14" pipeline to an aquifer $330 \mathrm{~km}$ away from the power plant. The aquifer needs to be prepared for $\mathrm{CO}_{2}$ injection.

- CCS + EOR: On top of the CCS system, the investment can be extended for $\mathrm{CO}_{2}$ EOR. The oil field has to be adapted for $\mathrm{CO}_{2}$ injection and a separation plant (with technology similar to the capture plant) has to be installed. If EOR would be the first choice, then the investment in the aquifer might be postponed until the end of the EOR activity. As of today, it is not clear that $\mathrm{CO}_{2}$ for EOR would earn credits for units of $\mathrm{CO}_{2}$ sequestered. However, we assume that this will be the case as long as it can be proved that the $\mathrm{CO}_{2}$ is sequestered. Therefore, having the aquifer

\footnotetext{
${ }^{3}$ We assume a capture rate of $85 \%$. Remaining emissions will need to be covered by emission permits in any case. 
Fig. 2 In state 1 the option is to vent the $\mathrm{CO}_{2}$, in state 2 the option is to invest in CCS and then jump to state 4 which is to store the $\mathrm{CO}_{2}$ in an aquifer. State 3 invests in CCS + EOR at the same time, and then switches to a state where EOR is done for at most 10 years (from state 6 to state 13). In state 5 we are already storing the $\mathrm{CO}_{2}$ in the aquifer and then we invest in EOR. States 6 to 13 represent EOR starting from 2016 to 2023

Table 1 Investment and operational costs (in 2005 NOK)

available for use from the beginning is considered to be a backup mechanism to ensure continued sequestration.

- Venting: The alternative of not investing in CCS is also possible. In this case, carbon allowances have to be purchased.

See Fig. 2 for the representation of the different states of investment, and of capture and storage of $\mathrm{CO}_{2}$. The transition matrix $\tau_{t}$ is based on this information.

Table 1 shows the costs used in our analysis, which are obtained from studies on Tjeldbergodden (a projected gas power plant in Norway). The values have been updated to 2012 currency units, using the CEPCI index until 2008 and a estimated inflation rate $(2.5 \%)$ for the rest of the years.

The technology for large-scale $\mathrm{CO}_{2}$ capture is still being developed. Investment costs for $\mathrm{CO}_{2}$ capture are expected to be lower as the technology becomes more mature, and a yearly reduction of $2 \%$ is assumed. Technology for $\mathrm{CO}_{2}$ transport is very similar to the natural gas transport, which has been used for many years and is a well established and mature technology. Also, technology for $\mathrm{CO}_{2}$ injection, either in an aquifer or in an oil field, can be transferred from the oil and natural gas industry. Construction costs are attributed to the year in which the facility begins operation, although in reality construction may take more years, and costs would be 
spread across the construction period. In doing so, we are slightly overestimating the construction costs.

All the values presented are adjusted by the inflation, which we assume to be $2.5 \%$ as this is the goal of the Norwegian Government's monetary policy.

\subsection{EOR model}

Oil recovery methods can be grouped into conventional and enhanced methods. Conventional recovery involves production of oil through natural reservoir pressure or by waterflooding, where water is injected into the reservoir to maintain reservoir pressure and displace the oil. Conventional recovery ceases when the oil production rate is too low to offset the cost of operating the field. At this point, typically $40 \%$ to $60 \%$ of the original oil in place remains trapped in the reservoir. Enhanced oil recovery methods allow additional oil to be extracted economically from the reservoir. One of the possible EOR methods is the injection of $\mathrm{CO}_{2}$, where the $\mathrm{CO}_{2}$ dissolves in the oil and improves oil displacement into the production wells. The exact response to $\mathrm{CO}_{2}$ flooding varies for each specific field. Recovery rates of additional oil can be only estimated through specific simulation models that involve technical details of the particular reservoir. In this case, the recovery ratio (the number of additional barrels of oil produced for each tonne of $\mathrm{CO}_{2}$ injected) shown in Fig. 3 (above) is an estimate taken from [7]. As can be observed, the recovery ratio is low the first years before peaking and then starts declining.

Shortly after the $\mathrm{CO}_{2}$ injection starts, the $\mathrm{CO}_{2}$ will break through and some of the $\mathrm{CO}_{2}$ injected will slip to the surface. $\mathrm{CO}_{2}$ then is separated, conditioned and reinjected into the reservoir; therefore, the amount of $\mathrm{CO}_{2}$ injected increases with the time. Figure 3 (below) shows the $\mathrm{CO}_{2}$ re-cycling ratio: tonnes of $\mathrm{CO}_{2}$ that resurface for each tonne of $\mathrm{CO}_{2}$ injected. The injection of $\mathrm{CO}_{2}$ ceases after 10 years and before 2030 (year when the field is projected to shut down).

Since the injection of $\mathrm{CO}_{2}$ cannot start too early and cannot be delayed too much because the field may be decommissioned before the EOR investment is paid back,

Fig. $3 \mathrm{CO}_{2}$-EOR profile-(above) EOR ratio is the number of extra barrels of oil produced for each tonne of $\mathrm{CO}_{2}$ injected; (below) $\mathrm{CO}_{2}$ re-cycling ratio is the amount of $\mathrm{CO}_{2}$ that re-cycles for each tonne of $\mathrm{CO}_{2}$ injected
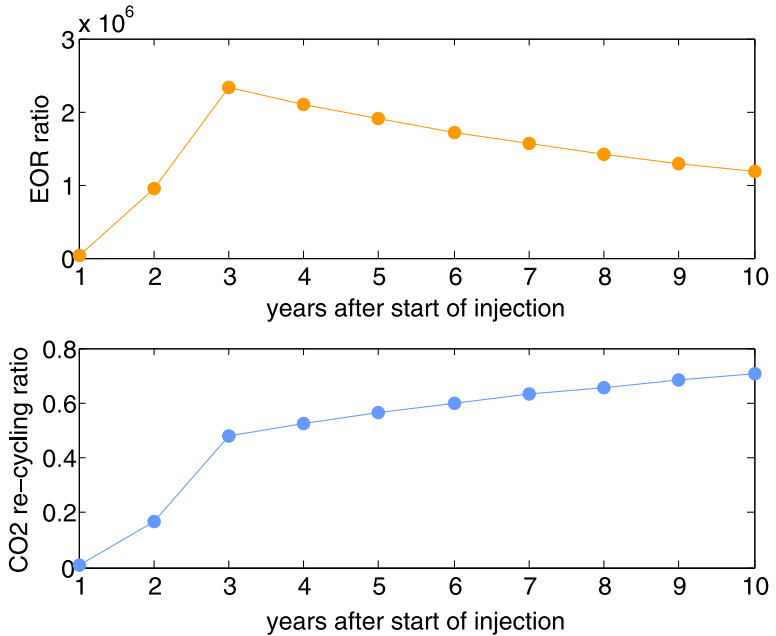
Table 2 Value of the parameters of (1) for the oil and the $\mathrm{CO}_{2}$ price. The correlation is $\rho=0.87$

Fig. 4 Oil and $\mathrm{CO}_{2}$ samples from the binomial lattice

\begin{tabular}{llll}
\hline & $P_{2012}$ & $\mu$ & $\sigma$ \\
\hline Oil & $70 \mathrm{USD} / \mathrm{bbl}$ & 0.0111 & $7.75 \%$ \\
$\mathrm{CO}_{2}$ & $14 \mathrm{EUR} /$ tonne & 0.0093 & $7.75 \%$ \\
\hline
\end{tabular}

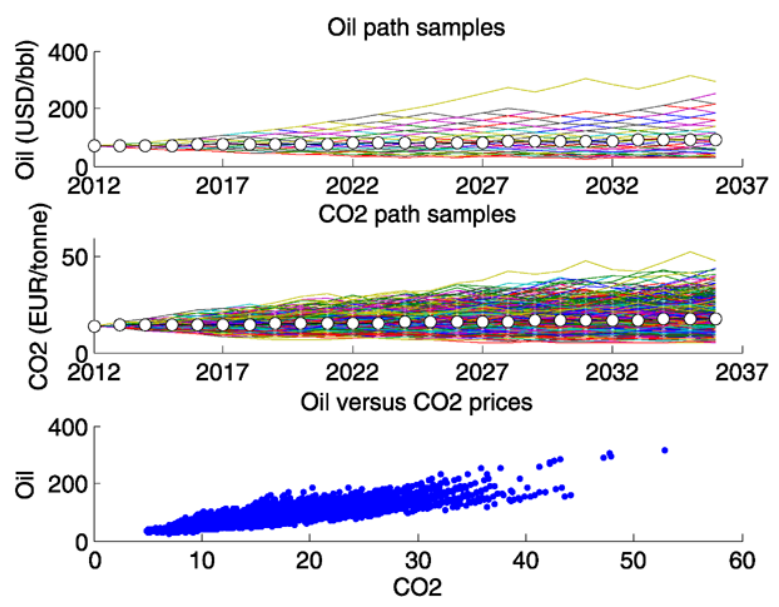

the injection of $\mathrm{CO}_{2}$ for EOR has a specific time window. For the oil field used in our study, $\mathrm{CO}_{2}$-EOR cannot start before 2016 and no later than 2023.

\subsection{Uncertainty representation}

Oil and carbon prices are modelled by means of a binomial lattice representing the two correlated variables. Table 2 presents the values used. ${ }^{4}$ The price in 2012 is based on the observed prices from April 2009 to March 2010. The expected drift has been calculated from the forecasts in the Baseline scenario used by the European Commission [4]. ${ }^{5}$ The annual price volatility estimates and the correlation between the two commodities are from Yang et al. [16].

Figure 4 shows a sample from the binomial lattice of the oil and $\mathrm{CO}_{2}$ price paths. The central white dots depict the expect value of the price at each time period. The scatter plot in the bottom plots the $\mathrm{CO}_{2}$ price against the oil price where it is appreciated the high correlation between the two commodities.

\section{Results and sensitivity analysis}

By analysing the results of the base case presented, we wish to understand how the use of $\mathrm{CO}_{2}$ for EOR influences the profitability and timing of a CCS project and what are the main drivers of the expected NPV.

\footnotetext{
${ }^{4}$ The currency of the model is MNOK. When it is required, a fixed rate of 8 NOK/EUR and 6.5 NOK/USD is used.

${ }^{5}$ Forecasts are only until 2020, and the same drift was assumed to be valid until 2036.
} 
Table 3 Expected NPV (in $\mathrm{MNOK}$ ) for the given choices

Fig. 5 Probability of being at each state in each time period (above) and oil and price distribution in 2019 (below)

\begin{tabular}{lr}
\hline Decision & $\mathbb{E}(\mathrm{NPV})$ \\
\hline Always vent $\mathrm{CO}_{2}$ & -4472 \\
Invest in CCS from $t=1$ & -19807 \\
Invest in CCS + EOR (DP solution) & -477 \\
\hline
\end{tabular}

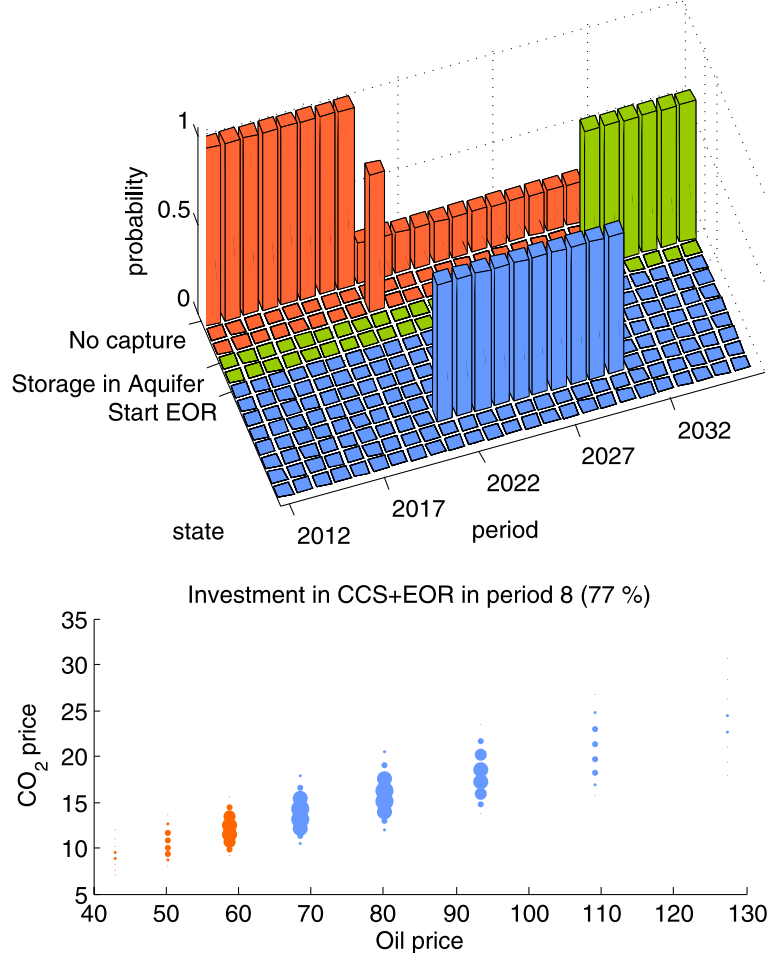

Table 3 shows the expected NPV when the only choice is to vent the $\mathrm{CO}_{2}$. During the 25 years, the power plant would spend on average 4472 million NOK on emission permits. The investment in CCS is even more unfavourable, thereby meaning that the (estimated) level of the $\mathrm{CO}_{2}$ price by itself does not promote investment in CCS. The focus shifts when there is the option to use the $\mathrm{CO}_{2}$ for EOR, where the losses are reduced to -477 (according to the solution found by DP). However, the profits obtained from the oil are not sufficient for producing a positive NPV.

Given the underlying uncertainty in the oil and $\mathrm{CO}_{2}$ prices and the results from the DP solution, we can compute the probability of being in a particular state at each time period. Figure 5 (above) plots these probabilities (see Fig. 2 for an explanation of the states). The strategy to follow looks clear. The power plant emits $\mathrm{CO}_{2}$ until 2020 when, with a probability of $77 \%$, it invests in CCS + EOR and in 2021 starts capturing the $\mathrm{CO}_{2}$ and using it for EOR. Year 2021 is the last year where there will 
be 10 years of EOR. After 10 years of $\mathrm{CO}_{2}$-EOR operations, the $\mathrm{CO}_{2}$ is stored in the aquifer.

The question that arises with this picture is why the investment in CCS does not happen earlier (if the investment is done in 2020 anyhow). The inflation and the discount rate play a role in hiding some of the effects, as well as the learning curve used for the capture costs. However, if we inspect the results closely then we see that the main difference is due to the high operating cost of the CCS. The savings from not buying $\mathrm{CO}_{2}$ allowances do not compensate for the operating costs of the capture plant.

Figure 5 (below) shows the oil and $\mathrm{CO}_{2}$ price distribution that encourages investment in CCS + EOR. The size of the dot is proportional to the probability of being in such a price pair. The rule observed is that for low oil prices, the optimal decision is to keep on venting the $\mathrm{CO}_{2}$, while for higher oil prices (from around 65 USD on) the best decision is to invest in CCS + EOR. Since the range of the $\mathrm{CO}_{2}$ price does not change the investment decision rule, we conclude that the $\mathrm{CO}_{2}$ price does not to affect the decision.

In order to see the effect that price uncertainty has over the profitability of the value chain, we examine the distribution of the NPV. Given the oil and $\mathrm{CO}_{2}$ price distributions, computing the exact variance of the model is prohibitive due to the exponential number of possible paths that the prices can follow. We have sampled 50000 price paths from the lattice. Each price path is a sequence of price pairs (oil and $\mathrm{CO}_{2}$ ) for each time period. At each point, the decisions made are the ones obtained from the DP solution. In order to analyse statistically the distribution of the NPV, the sampling process has been repeated 100 times (see Fig. 6 (above)). It is a nonsymmetric distribution, strongly skewed to the right. The shape clearly suggests that the distribution is a combination of two underlying distributions, which are plotted below. One corresponds to the NPV distribution when investment in CCS + EOR occurs (77\% of the cases), and the other for the situation where there is no investment. We can see that the NPV distribution when investment happens has more variability than for the non-investment one. However, values are more spread to the positive

Fig. 6 NPV distribution according to the underlying oil and $\mathrm{CO}_{2}$ price distribution and the strategy set by the DP solution
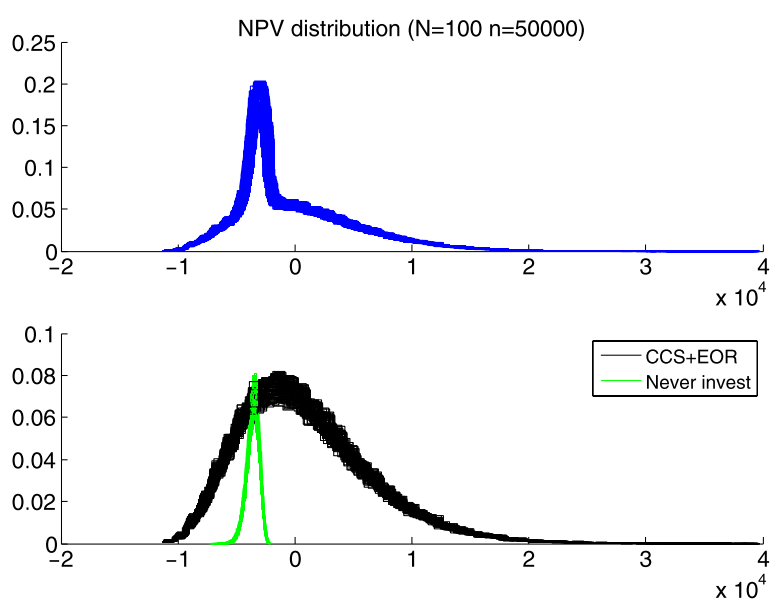

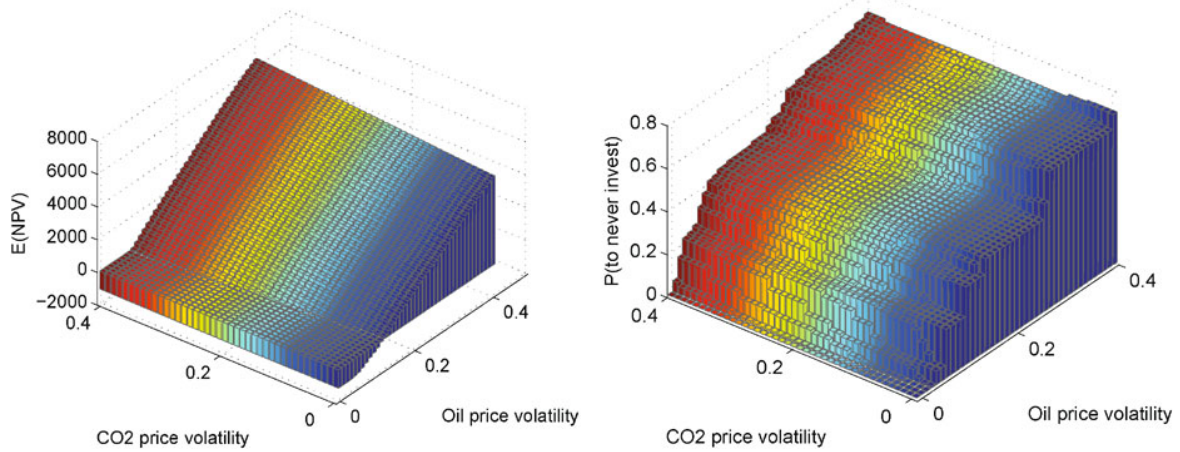

Fig. $7 \mathbb{E}(\mathrm{NPV})($ left $)$ and probability of not investing (right), when varying the annual volatility $(\sigma)$

part than for the negative one. This indicates that, although the risk is high, there are possibilities of making large profits.

\subsection{Sensitivity analysis}

In this section, we focus on how the analysis performed in the previous sections may vary when some of the data change. We start by looking at the effect of volatility. Figure 7 (left) displays the expected NPV solution when the annual volatility changes. The expected NPV solution is higher when the volatility grows, as the chances for increasing revenues are also higher. However, this increase is at the expense of reducing the probability of investing in CCS. The effect of the volatility of the $\mathrm{CO}_{2}$ and oil price are unequal. Observe that the increase in the oil volatility delays the finding of a solution with positive expected NPV more than for the $\mathrm{CO}_{2}$ volatility. Therefore, the driver for investing in CCS (+EOR) is the income and not the avoided costs due to $\mathrm{CO}_{2}$ emissions.

On the other hand, the higher the values of the volatility of the $\mathrm{CO}_{2}$ price the higher is the probability of venting the $\mathrm{CO}_{2}$ for the whole period. This result suggests that uncertainty around the $\mathrm{CO}_{2}$ price leads to a postponement of the investment in CCS. Given that the $\mathrm{CO}_{2}$ price it is not only driven by market rules but also by political decisions, governments should give clear signals about their environmental policy in order to reduce the sources of uncertainty. Note that for the deterministic case (when volatility is equal to 0 ) the probability of investing is 1 although the $\mathbb{E}(\mathrm{NPV})$ has its lowest value (but still higher than the option of not investing in CCS or only in CCS with aquifer storage).

Another component that defines the price is the drift. Figure 8 (left) displays how the expected NPV changes with the drift and the probability of never investing in CCS (right). ${ }^{6}$ Starting always as indicated in Table 2, the price at the last period varies from 20 to 140 USD for the oil, and from 0 to 60 EUR for the $\mathrm{CO}_{2}$. Since a higher drift implies higher future prices, we observe that higher $\mathrm{CO}_{2}$ prices delay positive

\footnotetext{
${ }^{6}$ Note the reverse axis in this plot.
} 

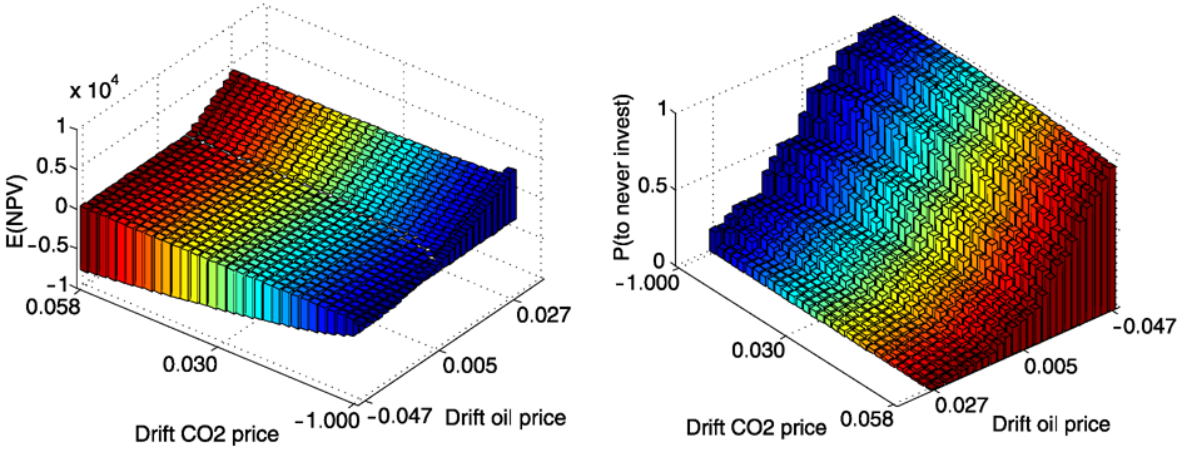

Fig. $8 \mathbb{E}(\mathrm{NPV})($ left $)$ and probability of not investing (right), when varying the annual drift $(\mu)$

NPV investments, although the probability of investing increases with higher prices. In the extreme case that the $\mathrm{CO}_{2}$ price goes to zero, the NPV is rather small due to the low costs of the carbon permits (the probability of investment is 0 ). However for final prices greater than 35 USD ( $\mu^{\text {oil }}=-0.026$ ) the probability of investing in $\mathrm{CCS}+\mathrm{EOR}$ starts to increase. Analysing the distribution of the probability of not investing, it is seen that for low prices CCS investment will never happen, and that for high prices investment will always occur.

The sensitivity analysis of the correlation between both commodities shows that a change in this parameter influences the final outcome very little, although the higher the correlation the better is the expected NPV. The expected NPV changes linearly from -610 MNOK when $\rho=0$ to -459 MNOK when $\rho=1$.

\section{Conclusion}

In this paper we have investigated the profitability of several value chains for large $\mathrm{CO}_{2}$ producers. The alternatives to venting the $\mathrm{CO}_{2}$ and buying (from 2012 on) $\mathrm{CO}_{2}$ allowances are: to invest in a CCS system with storage in an aquifer; or to extend the CCS investment with EOR. The use of $\mathrm{CO}_{2}$ for EOR is plausible for oil producer countries (such as the North Sea area), or if there is an adequate infrastructure for $\mathrm{CO}_{2}$ transport and regulations support this.

The main conclusion is that the combination of CCS with EOR will result in a situation more profitable (although still with negative expected NPV) than venting the $\mathrm{CO}_{2}$ or investing and running only the CCS infrastructure. There is a time window for initiation of EOR, and the results indicated that the optimal timing for investing will most likely be around 2020, the last period where EOR will last for 10 years (maximum number of years allowed for the base case used). It is clear also that oil revenues from EOR are the main driver for CCS + EOR implementation. Due to the high operating costs of the capture plant, avoided costs for $\mathrm{CO}_{2}$ allowances do not pay off an earlier investment on the CCS part.

The analysis of investment includes uncertainty in the $\mathrm{CO}_{2}$ allowance price and in the oil price. Higher volatility in the prices shows a major potential for a positive expected net present value, but at the expense of postponing the investment in the 
mitigation technology. On the other hand, higher drift rates increases the chances of investing in CCS + EOR and having positive expected NPV.

Acknowledgements The research leading to these results has received funding from the European Community's Seventh Framework Programme (FP7/2007-2013) under grant agreement No. 218868 (The ECCO project), by the Research Council of Norway through project 178374/S30, and by the ELDEV project at Sør-Trøndelag University College. We recognise the Norwegian research centre CenSES, Centre for Sustainable Energy Studies. The authors thank the comments and suggestions of A. Siddiqui of University College London and anonymous reviewers.

Open Access This article is distributed under the terms of the Creative Commons Attribution Noncommercial License which permits any noncommercial use, distribution, and reproduction in any medium, provided the original author(s) and source are credited.

\section{References}

1. The EU emissions trading scheme. European Commission (2008)

2. Abadie, L.M., Chamorro, J.M.: European $\mathrm{CO}_{2}$ prices and carbon capture investments. Energy Econ. 30(6), 2992-3015 (2008)

3. Dixit, A.K., Pindyck, R.S.: Investment Under Uncertainty. Princeton University Press, Princeton (1994)

4. Commission Staff Working Document. Europe's current and future energy position. Demandresources_investments. Technical report, European Commission, Brussels (2008)

5. Fuss, S., Szolgayova, J., Obersteiner, M., Gusti, M.: Investment under market and climate policy uncertainty. Appl. Energy 85(8), 708-721 (2008)

6. Heydari, S., Ovenden, N., Siddiqui, A.: Real options analysis of investment in carbon capture and sequestration technology. Comput. Manag. Sci., 1-30 (2010). doi:10.1007/s10287-010-0124-5

7. Holt, T., Lindeberg, E.: A techno-economical model for large scale deposition of $\mathrm{CO}_{2}$ in oil reservoirs and aquifers. Technical report, SINTEF Petroleum Research (2004)

8. Hull, J.C.: Options, Futures and Other Derivatives, 7th edn. Prentice Hall, New York (2008)

9. Klokk, Ø., Schreiner, P., Pagès-Bernaus, A., Tomasgard, A.: Optimizing a $\mathrm{CO}_{2}$ value chain for the Norwegian continental shelf. Energy Policy 38(11), 6604-6614 (2010)

10. Kvamsdal, H.M., Mejdell, T., Steineke, F., Weydahl, T., Aspelund, A., Hoff, K.A., Skouras, S., Barrio, M.: Tjeldbergodden power/methanol $-\mathrm{CO}_{2}$ reduction efforts. Technical report, SINTEF (2005)

11. Metz, B., Davidson, O., de Coninck, H., Loos, M., Meyer, L.: IPCC Special Report on Carbon Dioxide Capture and Storage. Cambridge University Press, Cambridge (2005)

12. Commission of the European Communities. 2020 by 2020 Europe's climate change opportunity (2008)

13. Gaspar Ravagnani, A.T.F.S., Ligero, E.L., Suslick, S.B.: $\mathrm{CO}_{2}$ sequestration through enhanced oil recovery in a mature oil field. J. Pet. Sci. Eng. 65(3-4), 129-138 (2009)

14. Schwartz, E., Smith, J.E.: Short-term variations and long-term dynamics in commodity prices. Manag. Sci. 46(7), 893-911 (2000)

15. Statoil and Fluor. Tillegg til konsekvensutredning for utvidelse av metanolfabrikk og bygging av gasskraftverk på Tjeldbergodden. Technical Report PMT-RAPP 00004 (2005)

16. Yang, M., Blyth, W.: Modeling investment risks and uncertainties with real options approach. Working paper for an IEA book: Climate policy uncertainty and investment risk, IEA (2007) 